\title{
Taxa não é Cobrança: U ma Proposta para a Efetiva Aplicação do Instrumento de Gestão dos Recursos Hídricos para a Drenagem U rbana
}

\author{
Geraldo Lopes da Silveira \\ Departamento deEngenharia Sanitária e A mbiental/ UFSM \\ geraldo.ufsm@gmail.com \\ Francisco R. Forgiarini e Joel Avruch Goldenfum \\ Institu to de Pesquisas H idráulicas -UFRGS \\ francisco_forgiarini@yahoo.com.br , j.goldenfum@gmail.com \\ Recebido: 28/07/08 - revisado: 02/08/09 - aceito: 27/11/09
}

RESUM 0

A tualmente, em trabalhos acadêmicos e em alguns municípios brasileiros (por exemplo, Porto Alegre/ RS), discutese a criação de uma cobrança pelo serviço de drenagem urbana, semelhante à que existe em Santo Andrél SP. Além dessa cobrança, também deve ser utilizada a cobrança pelo uso da água, in strumento de gestão dos recursos hídricos. Observa-se nos trabalhos desenvolvidos na área certo conflito quanto ao con ceito e a plicação dessas cobran ças. Assim, o objetivo desse artigo é distinguir as duas cobran ças e propor uma estratégia para aplicá-las de forma articulada e efetiva, procu rando minimizar os impactos da urbanização sobre o ciclo hidrológico. Para isso, pretendese responder as seguintes perguntas: "Quais os objetivos dos pagamentos? Quem deve pagar? Quem administra os recursos gerados? Onde devem ser aplicados esses recursos?" A partir de uma revisão crítica de trabalhos, chegou-se a seguinte constatação: a cobrança pelo serviço de drenagem urbana é uma taxa e a cobrança pelo uso da água é um preço público. Portanto, são pagamentos distintos, com objetivos também distintos. 0 pagamento da taxa objetiva promover o fun cionamento do serviço da drenagem urbana e o preço público está relacionado à conservação da bacia hidrográfica como um todo, em uma visão condominial, sen do que os recursos gerados pela cobrança podem ser aplicados em diferentes ações na bacia. Nesse contexto, definese a cobrança da taxa pelo serviço é interna ao município, devendo ser paga pelos proprietários dos imóveis ao município; e a cobrança pelo uso da água é externa ao município, referente aos impactos proporcionados pelo município à bacia hidrográfica. É feita uma aplicação da proposta na Bacia do rio Santa Maria/RS. As simulações indicam uma relação de aproximadamente 1/20 ( $R \$ 39,34 / R \$ 823,78)$ por habitante na comparação Cobrança/ Taxa para a bacia como um todo. As duas cobranças geram arrecadações que serão repassadas ao município e ao comitê de bacia, respectivamente, viabilizando investimentos em ações estrutu rais e, principalmente, não estruturais para a drenagem urbana.

Palavras-chave: cobrança pelo uso da água, taxa pelo serviço, drenagem urbana.

\section{INTRODUÇÃO}

Nas últimas décadas, os municípios brasileiros apresentaram um processo acelerado e não planejado de urbanização. 0 desenvolvimento deste processo produziu grandes alterações no ambiente urbano promovendo perdas materiais e humanas e problemas sociais de diversas magnitudes, especialmente devido às inundações e à poluição dos mananciais superficiais e subterrâneos.

Mostra-se evidente, portanto, a necessidade de alterar 0 atual paradigma de planejamento e gestão da drenagem de águas pluviais no Brasil.
Atualmente, o meio técnico-científico tem discutido a aplicação de alternativas que estejam mais próximas da sustentabilidade, o que, para a drenagem urbana representa a reprodução do comportamento hidrológico natural (Psat \& Wsu, 2005).

Algumas ações promissoras têm sido trabalhadas nas municipalidades brasileiras, com o emprego de técnicas compensatórias ( ou Best M anajement Practices BMPs), e em outros países por meio de estratégias desenvolvidas a partir dos anos 1990, como por exemplo, o Low I mpact Development (LID) nos Estados Unidos e Water Sensitive Urban Design (WSUD) na Austrália. No entanto, Silveira e Goldenfum (2004), Goldenfum et al. (2007) e Cruz et al (2007) enfati- 
zam que ainda há grande resistência por parte dos projetistas brasileiros à aplicação destas técnicas, pois existe pouca divulgação e obras executadas, além da oposição natural a inovações. Neste sentido, reforça-se a necessidade de se pensar a drenagem urbana como parte de um sistema de gestão e não apenas al gumas obras de controle de enchentes que são definidas após a constatação de algum problema, conforme discutido por Pompêo (2000).

Com objetivo de minimizar os impactos sobre o ciclo hidrológico, tanto na escala municipal quanto na escala de bacia hidrográfica, diversos autores (tais como, Doll e Lindsey, 1999; Souza, 2005; Kathuria, 2006) indicam a necessidade de trabalhar mecanismos de incentivo e financiamento à implementação de um planejamento sustentável da drenagem urbana. De acordo com Baptista et al. (2005), no Brasil e em outros países, tem-se discutido a adoção deste incentivo e financiamento por meio de uma taxa específica pelo uso do sistema de drenagem de águas pluviais. Os autores apontam os estudos de Tucci (2002); Baptista e Nascimento (2002); e Gomes (2005) que procuraram estabelecer uma cobrança pelo serviço de drenagem urbana.

No Brasil, a experiência pioneira é o município de Santo André, São Paulo, que cobra desde o ano de 1998. De acordo com SNSA (2005), com a cobrança da drenagem, o Serviço Municipal de Saneamento Ambiental de Santo André (Semasa) arrecada cerca de R\$ 6 milhões por ano, o que é suficiente para cobrir $50 \%$ dos gastos de manutenção da rede (limpeza de bocas-de-lobo, galerias, limpeza e desassoreamento de córregos, etc.).

Baptista et al. (2005) argumentam que a cobrança pelo serviço de drenagem de águas pluviais encontra respaldo na Lei Federal 9.433/ 1997, a lei das Águas, que instituiu a cobrança pelo uso da água como um dos cinco instrumentos de gestão dos recursos hídricos. Contudo, o entendimento defendido no presente artigo é que aquela cobrança não possui as características da cobrança pelo uso da água regulamentada na referida lei e que a definem como um preço público.

Assim, o objetivo deste artigo é discutir o conceito de cobrança pelo uso da água e propor uma estratégia para aplicá-la de forma articulada e efetiva com uma taxa pelo serviço de drenagem urbana. Para tanto, serão discutidas as diferenças entre os dois tipos de pagamentos e proposta a articulação de ambos, que objetivam, em última análise, melhorar os aspectos quantitativos e qualitativos dos recursos hídricos no ambiente urbano e na bacia hidrográfica como um todo.
COBRANÇA PELO USO DA ÁGUA E A COBRANÇA PELO SERVIÇO DE DRENAGEM URBANA: A COBRANÇA E A TAXA

A discussão que se propõe sobre as diferenças entre a cobrança pelo uso da água e cobrança pelo serviço da drenagem urbana não pretende ser extensa, uma vez que o assunto já foi objeto de estudos na área. 0 que se busca a partir da distinção dos dois pagamentos é responder as seguintes questões: Quais os objetivos dos pagamentos? Quem deve pagar? Q uem administra os recursos gerados? Onde devem ser aplicados estes recursos?

Cançado \& al. (2006) debatem a definição jurídica de uma cobrança pelo serviço de drenagem. Os autores argumentam que a cobrança pelos serviços públicos pode ser via tarifa ou taxa e que a diferença entre ambos reside na obrigatoriedade de uso do serviço público pela população, quando o mesmo é disponibilizado à sociedade pela administração pública. $\mathrm{E}$, devido a isto, os autores concluem que a cobrança pelo serviço da drenagem urbana caracteriza-se como uma taxa, pois o seu uso é obrigatório quando ocorre um evento chuvoso.

Por outro lado, no que se refere à natureza jurídica da cobrança pelo uso da água, também existiu a discussão sobre considerar a cobrança uma taxa ou uma tarifa. De acordo com Pereira (2002), essa mesma indefinição faz com que a redevance do Sistema Francês, com mais de 30 anos de existência e inspirador do sistema de gestão de recursos hídricos brasileiro, permaneça sob suspeita a respeito de sua legalidade. A Lei Federal 9.433/ 1997, ao utilizar o termo genérico "cobrança pelo uso dos recursos hídricos", deixou em aberto essa questão (Pereira, 2002).

Para Pompeu (1997) a cobrança prevista na Lei 9.433/ 1997 (ou contraprestação pela utilização das águas públicas) se define da seguinte forma:

a) não configura imposto (já que esse, conforme o Art. 16, da Lei Federal no 5.172/66, "destina-se a cobrir despesas feitas no interesse comum, sem ter em conta as vantagens particulares obtidas pelos contribuintes");

b) não é taxa (já que, conforme o Art. 77, da Lei Federal no 5.172/ 66, "não se está diante do exercício de poder de polícia -taxa de polícia —u da utilização efetiva ou potencial de serviço público -taxa de serviço");

c) não é contribuição de melhoria (já que, conforme o Art. 81, da Lei Federal no 
5.172/ 66, "inexiste obra pública cujo custo deva ser atribuído à valorização de imóveis beneficiados").

Desse modo, Pompeu (1997) argumenta que se está diante de um preço público, que são parte das Receitas Originárias, denominadas assim porque sua fonte é a exploração do patrimônio público. Por esse motivo são também chamadas Receitas Industriais ou Patrimoniais, pois são provenientes da exploração de serviços, bens, empresas ou indústria do próprio Estado.

Cánepa et al. (1999) concordam com a definição de Pompeu, ou seja, para eles o mecanismo de cobrança não visa atuar como um taxa. Para os autores o princípio que rege a cobrança pelo uso da água é que se trata de um preço público, ou seja, o pagamento pela utilização de um bem público para o beneficio particular. Já uma taxa é entendida com um tributo obrigatório exigido ao contribuinte pelo governo para a prestação de um serviço público fundamental. O s seus valores dependem apenas do serviço prestado, vinculados ao seu desenvolvimento, operação e manutenção. O u seja, o pagamento da taxa objetiva promover o funcionamento do serviço de drenagem urbana.

Por sua vez, a cobrança pelo uso da água, utilizada como um instrumento de gestão dos recursos hídricos, deve arrecadar recursos para dar suporte financeiro ao sistema de gerenciamento e às ações definidas pelos planos de bacia hidrográfica. Além disso, a cobrança deve indicar para a sociedade que a água é um bem escasso e que possui um valor, com a finalidade de que este recurso seja utilizado de forma racional e que o seu uso atenda aos princípios do desenvolvimento sustentável.

Assim, chega-se a seguinte conclusão: a cobrança pelo serviço de drenagem urbana é uma taxa e a cobrança pelo uso da água é um preço público. Portanto, são pagamentos distintos com objetivos também distintos. A partir desta constatação será apresentada a proposta de articulação dos pagamentos em função de quem deve pagar, quem administra os recursos financeiros gerados e onde os mesmos devem ser aplicados.

\section{PROPOSTA DE ARTICULAÇÃO ENTRE A COBRANÇA E TAXA PARA A DRENAGEM URBANA}

Tucci e Meller (2007) apresentam a distinção entre os espaços de gestão das águas urbanas entre a bacia hidrográfica e o município (Tabela 1).
Conforme a tabela, cabe ao município evitar a transferência dos impactos gerados pela mancha urbana ao sistema de rios que compõe a bacia hidrográfica, conforme define também a Lei 11.445/2007, a Lei do Saneamento. Sendo assim, a gestão do ambiente interno das cidades deve atender aos condicionantes externos da bacia, com objetivo de minimizar os impactos e buscar a melhoria da quantidade e da qualidade da água no conjunto de sua área. O u seja, para a drenagem urbana, o planejamento que é realizado pelo município, ou conjunto de municípios numa região metropolitana, deve atender aos objetivos definidos para a bacia hidrográfica na qual ele se insere.

Desta forma, no contexto da gestão dos recursos hídricos o município é um usuário, produzindo impactos na qualidade e quantidade das águas no âmbito da bacia hidrográfica. Logo, os municípios devem assumir seus papéis na gestão dos recursos hídricos, responsabilizando-se pelo atendimento às metas do enquadramento, solicitando a outorga para o uso da água e se inserindo no processo de cobrança pelo uso da água, que deve ser paga pela administração municipal para o gestor da bacia, 0 comitê ou a agência.

E quem deve pagar a taxa pela drenagem? Os usuários do sistema de drenagem municipal, os proprietários dos imóveis. 0 município deve ser 0 responsável pela administração dos recursos financeiros gerados pela taxa de drenagem e os recursos devem ser aplicados na prestação do serviço de drenagem urbana. Já o comitê de bacia é o responsável pela administração dos recursos financeiros gerados pela cobrança pelo uso da água e os recursos devem ser aplicados principalmente em estudos e ações não estruturais definidas nos planos de bacia hidrográfica. Deve-se evitar a aplicação da arrecadação da cobrança pelo uso da água em ações estruturais, pois a mesma, em função dos impactos econômicos gerados aos usuários, será incapaz de financiar obras para todos os setores que utilizam os recursos hídricos (Forgiarini et al. 2008).

Reconhecendo-se esta realidade, a gestão pode ser realizada de acordo com a definição de espaços geográficos "internos" e "externos" à mancha urbana municipal. Ao ambiente "interno" das cidades, vinculam-se a gestão das sub-bacias "municipais" com elevado grau de urbanização. Estas bacias "municipais", embora não possam ser assim denominadas legalmente, seriam aquelas de baixa ordem e que se desenvolvem dentro do município. A gestão destas bacias urbanas, ou sub-bacias, devem evitar os impactos em duas escalas: 
Taxa Não é Cobrança: Uma Proposta para a Efetiva Aplicação do Instrumento de Gestão dos Recursos Hídricos para a Drenagem Urbana

Tabela 1 - Espaço de gestão das águas urbanas (Tucci e M eller, 2007).

\begin{tabular}{|c|c|c|c|c|}
\hline Espaço & Domínio & Gestores & Instrumento & Característica \\
\hline Bacia H idrográfica & $\begin{array}{l}\text { Estado ou } \\
\text { União }\end{array}$ & $\begin{array}{l}\text { Comitês de } \\
\text { Bacia } \mathrm{Hi} \text { - } \\
\text { drográfica } \\
\text { ou Agências }\end{array}$ & Plano de Bacia & $\begin{array}{l}\text { Gestão da quantidade e } \\
\text { qualidade da água no sis- } \\
\text { tema de rios que formam a } \\
\text { bacia hidrográfica, evitando } \\
\text { a transferência de impactos }\end{array}$ \\
\hline Município & $\begin{array}{l}\text { Município } \\
\text { ou Região } \\
\text { Metrop. }\end{array}$ & Município & $\begin{array}{l}\text { Plano Diretor Ur- } \\
\text { bano e Plano Inte- } \\
\text { grado de Esgota- } \\
\text { mento, Drenagem } \\
\text { Urbana e Resíduo } \\
\text { Sólido }\end{array}$ & $\begin{array}{l}\text { Minimização dos impactos } \\
\text { de quantidade e qualidade } \\
\text { dentro do município, nas } \\
\text { pequenas bacias urbanas, } \\
\text { sem transferir para o siste- } \\
\text { ma de rios }\end{array}$ \\
\hline
\end{tabular}

1. Junto à própria comunidade da região, procurando minimizar os efeitos na qualidade de vida em todas a suas dimensões; e

2. Em escala de bacia frente aos condicionantes externos previstos no Plano de Bacia $\mathrm{Hi}$ drográfica, à luz dos princípios da gestão dos recursos hídricos.

Neste contexto, pode-se definir que existem dois tipos de cobrança relacionada à drenagem urbana:

1. A cobrança de uma taxa pelo serviço, interna ao município, pago pelos proprietários dos imóveis ao município em função do serviço prestado, e;

2. A cobrança de um preço público pela água, externa ao município, referente aos impactos proporcionados pelo município à bacia hidrográfica.

Esta proposta busca que o município: (i) responda aos problemas ambientais causados pelas manchas urbanas em nível de bacia, e; (ii) incentive internamente os proprietários e a administração municipal a promover o controle das águas pluviais no perímetro urbano.

\section{APLICAÇÃO DA PROPOSTA À BACIA HIDROGRÁFICA DO RIO SANTA MARIA}

Os valores utilizados nesta pesquisa pretendem dar apenas uma ordem de grandeza e fazer uma aplicação preliminar da proposta desenvolvida. A sua aplicabilidade real não foi objeto de discussão. No entanto, entende-se que ela é possível e o fórum para sua discussão sejam os Comitês de Bacias Hi- drográficas. Para simplificar a aplicação e análise admitiu-se que os recursos seriam obtidos em um mesmo ano. Embora se saiba que em um caso real os valores poderiam ser acumulados em uma seqüência de anos, dentro de um fluxo de caixa da aplicação das ações. Assim, ao final deste fluxo, os resultados seriam semelhantes aos aqui apresentados.

A bacia hidrográfica do rio Santa Maria situa-se na fronteira sudoeste do Rio Grande do Sul (Figura 1), abrangendo uma área de $15.754 \mathrm{~km}^{2} . \mathrm{Na}$ bacia localizam-se seis municípios: Santana do Livramento; Dom Pedrito; Lavras do Sul; Rosário do Sul; Cacequi; e São Gabriel. Segundo IBGE (2000), a população total dos municípios é de 257.745 habitantes, $11,78 \%$ dela localizada na zona rural e $88,22 \%$ na zona urbana. Entretanto, a população que reside dentro da bacia é de aproximadamente 200.000, uma vez que as sedes dos municípios de São Gabriel e Lavras do Sul situam-se fora da bacia.

O Comitê de Gerenciamento da Bacia Hidrográfica do rio Santa Maria (CGBHSM) se constitui, juntamente com o Comitê da Bacia do rio dos Sinos e o Comitê da Bacia do rio Gravataí, em uma das primeiras experiências no Estado de aplicação de mecanismos de gestão. O CGBHSM foi criado com a edição do Decreto Estadual n 35.103 , de maio de 1994. Desde a sua implantação os seguintes instrumentos de gestão já foram estudados:

i. Enquadramento dos recursos hídricos (FEPAM, 2001);

ii. Outorga para uso da água (UFSM/SEMA, 2004a);

iii. Cobrança pelo uso da água (Balarine et al., 2000 e UFSM/ SEMA, 2004b). 
O Plano de Bacia ainda não possui um estudo específico. Entretanto, o Departamento de Recursos Hídricos do Estado está elaborando um Termo de Referência para a realização do Plano de Bacia, que será baseado em EUROESTUDIOS e NOVOTECNI (2003). A seguir descreve-se a aplicação da cobrança interna e externa pela drenagem urbana na Bacia do rio Santa Maria.

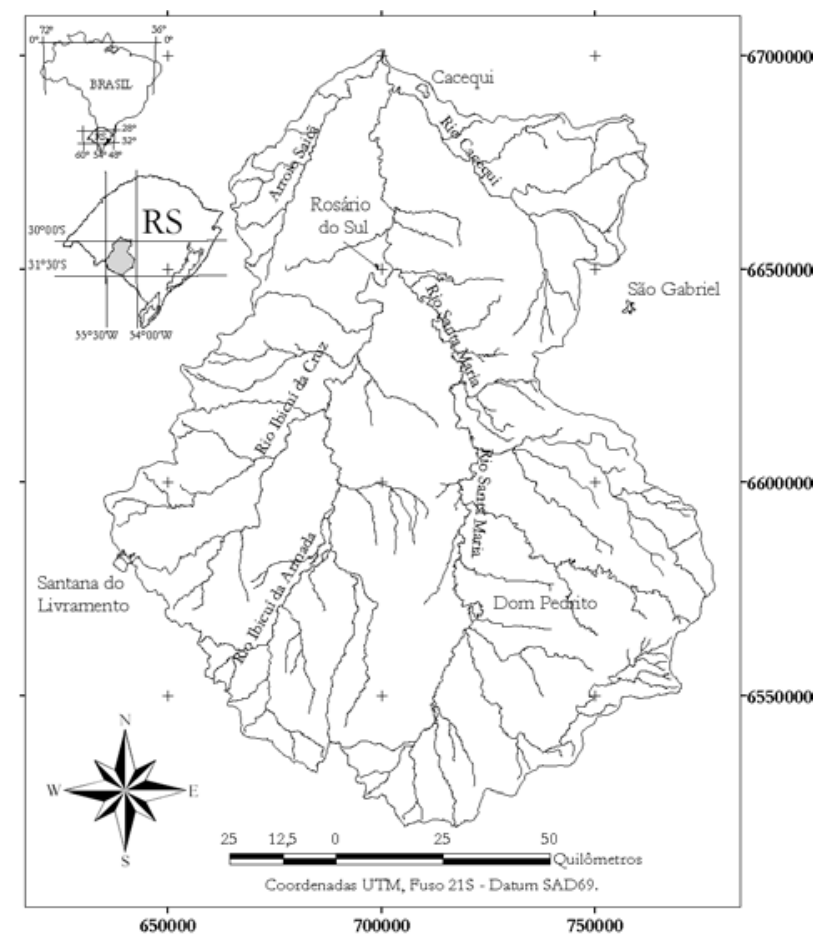

Figura 1 - Localização da bacia hidrográfica do rio Santa Maria.

Cobrança interna aos municípios:

Taxa pelo serviço de drenagem

Os municípios da bacia do rio Santa Maria não possuem Planos Diretores de Drenagem U rbana (PDDrUs). Em função da dificuldade de fazer uma avaliação das necessidades de investimentos nas áreas urbanas da bacia antes do desenvolvimento de estudos de diagnósticos dos problemas enfrentados, por simplificação, para a definição do valor do investimento nos PDDrUs foi utilizado o valor de $R \$ 2,5$ milhões por quilômetro quadrado de área urbana como referência. Este valor foi obtido a partir de Tucci (2007), que indica uma faixa de 1 a 4 milhões de reais por quilômetro quadrado, normalmente utilizada para a execução de obras de controle em escala de macrodrenagem. Utilizou-se o valor médio, pois não é certo que todas as áreas urbanas da bacia tenham problemas de drenagem pluvial que requeiram investimentos conforme apontados por Tucci (2007).

As áreas urbanas dos municípios analisados são apresentadas na Tabela 2, que apresenta também os recursos necessários para a execução dos PDDrUs. 0 investimento necessário para o controle da drenagem urbana nos municípios da bacia foi dividido pela população para ter uma ordem de grandeza que possibilitará comparações com a cobrança pelo uso da água. Nesta aplicação, não se pretendeu analisar a forma de rateio, que deve ser a mais eqüitativa possível e, de preferência, em função das alterações quantitativas (volumes e vazões máximas) e qualitativas (carga de lavagem de ruas e disposição inadequada de resíduos sólidos e líquidos) referentes às condições naturais do local urbanizado, conforme analisaram, por exemplo, Forgiarini et al. (2007).

$O$ valor médio para os municípios foi de $R \$$ 964,06 por habitante (variação de $R \$ 678,14 /$ hab a $R \$ 1358,27 /$ hab), para a bacia o valor foi de $R \$$ $823,78 /$ hab. Estes valores são semelhantes ao obtido por Cruz (2004), que analisou a situação atual do sistema de drenagem de Porto Alegre e determinou soluções otimizadas (mínimo custo) para os problemas de alagamentos. As soluções adotadas pelo autor foram a ampliação da micro e macrodrenagem e a construção de reservatórios de amortecimento, seguindo o planejamento de acordo com as técnicas compensatórias ou de BMPs. O custo total para as vinte e sete bacias hidrográficas do município de Porto Alegre foi de $R \$ 1.418 .934 .329,60$, que dividido pela sua população (1.383.454 habitantes IBGE, 2000) representa um valor de $R \$$ $1.025,64 /$ hab.

Cobrança externa ao município:

Cobrança pelo uso da água

Forgiarini et al. (2008) demonstram que a capacidade de arrecadação via cobrança pelo uso da água na bacia do Rio Santa Maria teria a possibilidade de financiar apenas estudos e elaboração de projetos. Assim, para a definição do valor de cobrança pelo uso da água, foram utilizados todos os componentes que continham estudos no trabalho de EUROESTUDIOS e NOVOTECNI (2003), apresentados na Tabela 3. Para obras, os estudos foram orçados em $10 \%$ do valor.

O trabalho das empresas espanholas pretendeu consolidar um documento que possa servir como base para a solicitação de financiamento aos organismos públicos nacionais, internacionais ou 
Taxa Não é Cobrança: Uma Proposta para a Efetiva Aplicação do Instrumento de Gestão dos Recursos Hídricos para a Drenagem Urbana

Tabela 2 - Áreas U rbanas dos municípios da bacia hidrográfica do Rio Santa Maria.

\begin{tabular}{l|l|l|l|l}
\hline Município & $\begin{array}{l}\text { Área Ur- } \\
\text { bana }\left(\mathrm{Km}^{2}\right)\end{array}$ & $\begin{array}{l}\text { Investimento } \\
(\mathrm{R} \$)\end{array}$ & $\begin{array}{l}\text { População } \\
(\mathrm{hab})\end{array}$ & $\mathrm{R} \$ /$ hab \\
\hline Cacequi & 6,9 & $17.250 .000,00$ & 12.700 & $1.358,27$ \\
\hline $\begin{array}{l}\text { Dom Pe- } \\
\text { drito }\end{array}$ & 14,06 & $35.150 .000,00$ & 36.998 & 950,05 \\
\hline $\begin{array}{l}\text { Rosário do } \\
\text { Sul }\end{array}$ & 12,81 & $32.025 .000,00$ & 36.819 & 869,79 \\
\hline $\begin{array}{l}\text { Santana do } \\
\text { Livramento }\end{array}$ & 24,5 & $61.250 .000,00$ & 90.320 & 678,14 \\
\hline Total & 58,27 & $145.675 .000,00$ & 176.837 & 823,78 \\
\hline
\end{tabular}

Tabela 3 - Estudos do programa de desenvolvimento da bacia hidrográfica do rio Santa Maria (adaptado de EUROESTUDIOS e NOVOTECNI, 2003).

\begin{tabular}{|c|c|c|c|}
\hline Componente & Sub-componente & Valor (US\$) & Valor $(\mathrm{R} \$)^{*}$ \\
\hline \multirow{6}{*}{ Controle Ambiental } & Ortoimagem Digital & $24.470,90$ & $40.376,99$ \\
\hline & Recadastramento imobiliário & $73.402,20$ & $121.113,63$ \\
\hline & $\begin{array}{l}\text { Ampliação da rede hidrometeoroló- } \\
\text { gica }\end{array}$ & $71.600,00$ & $118.140,00$ \\
\hline & Identificação de áreas de risco & $15.200,00$ & $25.080,00$ \\
\hline & Caracterização de vertidos & $18.200,00$ & $30.030,00$ \\
\hline & Cadastramento usuários da água & $21.200,00$ & $34.980,00$ \\
\hline \multirow{2}{*}{ Proteção de áreas de risco } & Proteção contra as inundações & $150.000,00$ & $247.500,00$ \\
\hline & Proteção contra a erosão & $2.722 .805,00$ & $4.492 .628,25$ \\
\hline \multirow{4}{*}{ Monitoramento Ambiental } & Qualidade de água & $76.000,00$ & $125.400,00$ \\
\hline & Vazões Ecológicas & $36.000,00$ & $59.400,00$ \\
\hline & Mata Ciliar & $2.160,00$ & $3.564,00$ \\
\hline & Áreas Reflorestadas & $2.160,00$ & $3.564,00$ \\
\hline \multirow{2}{*}{$\begin{array}{l}\text { Abastecimento, saneamento } \\
\text { e resíduos sólidos }\end{array}$} & Água e saneamento & $1.310 .478,70$ & 2.162.289,86 \\
\hline & Resíduos Sólidos U rbanos & $244.228,20$ & $402.976,53$ \\
\hline \multicolumn{2}{|l|}{ Total } & $4.767 .905,00$ & $7.867 .043,25$ \\
\hline
\end{tabular}

privados. Dessa forma, foi proposta uma série de ações, concebidas de tal forma, que se incluam em processos e dinâmicas próprias de desenvolvimento social, de maneira a contribuir a melhora da qualidade de vida da comunidade da bacia. $O$ valor de $\mathrm{R} \$$ 7.867.043,25 (Tabela 3) foi dividido pelo número de habitantes de toda a bacia, cerca de 200.000 , pois os estudos referem-se a toda a bacia, chegando-se ao valor de $\mathrm{R} \$ 39,34 / \mathrm{hab}$.

\section{Comparação T axa e Cobrança para a bacia do rio Santa M aria}

A metodologia proposta neste trabalho busca que o município responda aos problemas ambi- entais causados pelo perímetro urbano em escala de bacia, e busca incentivar a administração municipal e os usuários urbanos a promover o controle de suas águas pluviais. Os usuários urbanos pagariam uma taxa referente ao serviço de drenagem prestado pelo município, e; o município, configurando-se como um usuário dentro da bacia hidrográfica, pagaria pelos impactos causados aos recursos hídricos da sua área de abrangência. Estas cobranças gerarão duas arrecadações que potencializam a execução em parte dos planos diretores municipais e os planos de bacia hidrográfica.

A Figura 2 sintetiza os resultados obtidos. Nela são apresentados os investimentos nos PDDrUs individuais dos municípios e as respectivas taxas por 


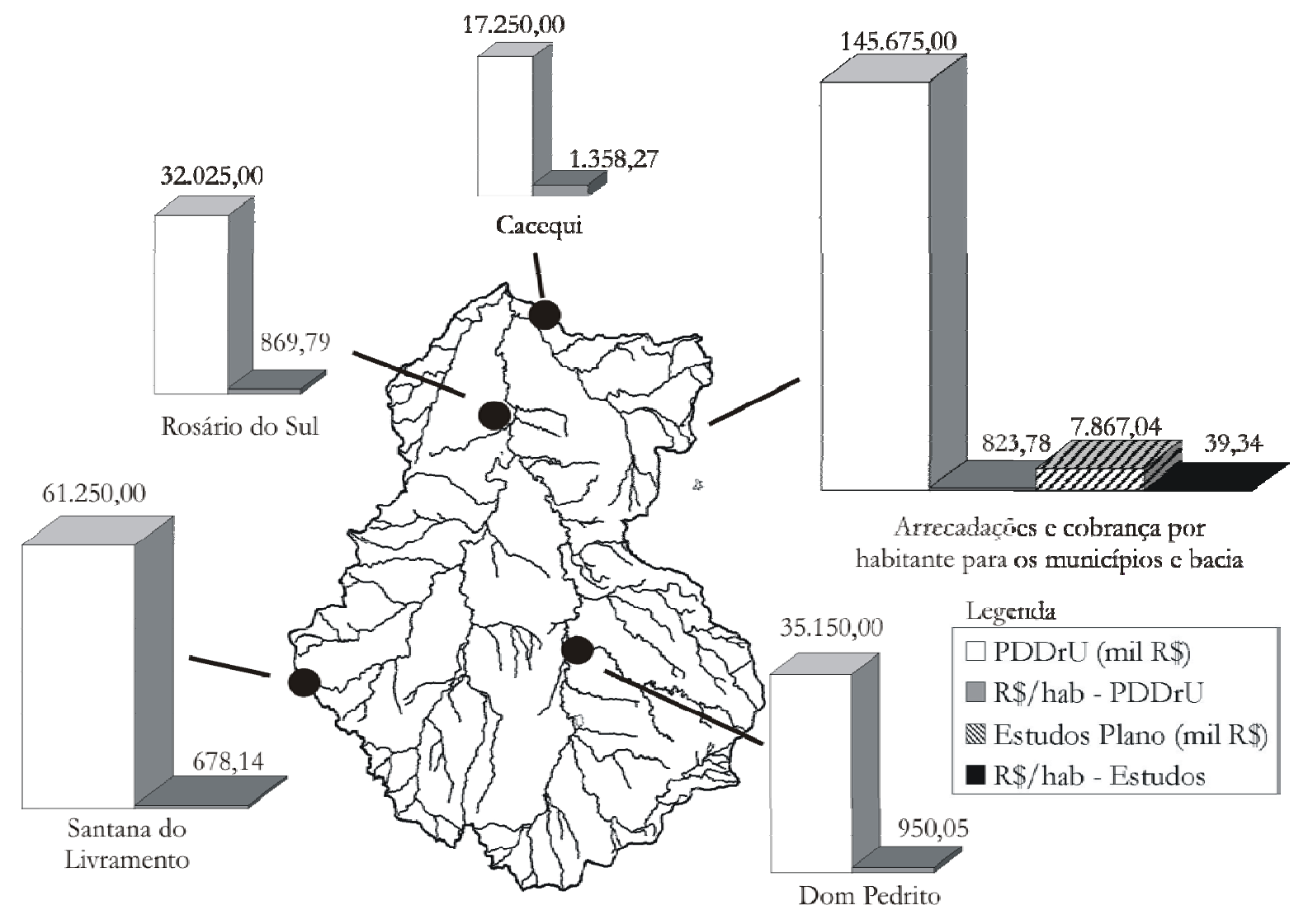

Figura 2 - Resultados comparativos da cobrança interna e externa aos municípios na bacia do rio Santa Maria.

habitante (Tabela 2) e a comparação das arrecadações necessárias para a realização de todos os PDDrU smunicipais e a cobrança pelo uso da água para financiar os estudos presentes em EUROESTUDIOS e NOVOTECNI (2003). As simulações indicam uma relação de aproximadamente 1/20 (R\$39,34/ $\mathrm{R} \$ 823,78)$ por habitante ano na comparação Cobrança/ Taxa para a bacia como um todo.

Quanto à cobrança "interna" ao município, admite-se ser possível que a cobrança específica pelo uso dos sistemas de drenagem, em forma de taxa, leve ao uso mais racional do solo urbano, ou uma maior consciência do impacto daquela propriedade (e da forma como foi construída) nos custos envolvidos no sistema de drenagem. Neste sentido a cobrança de uma taxa poderia proporcionar a execução e manutenção de ações estruturais no município.

Nesse sentido, ressalta-se a experiência de Santo André, que a partir da instituição da taxa foi possível fazer serviços que há muito tempo não eram feitos, como o desassoreamento do rio Tamanduateí, Ribeirão dos Meninos e Córrego Oratório (Semasa, 2007). O Tamanduateí, desassoreado em 1998, não era limpo havia 8 anos, causando grandes transtornos à cidade. É importante também deixar claro que os recursos provenientes da taxa de drenagem em Santo André não são usados para obras, o dinheiro é destinado apenas para manutenção, conforme prevê a Lei Municipal 7.606 de 23 de Dezembro de 1997.

Analisando a cobrança "externa" ao município, a cobrança pelo preço público da água, devese diferenciar o potencial de arrecadação e utilização dos recursos provenientes desta cobrança. Enquanto a cobrança interna ao município deve ser utilizada para financiar o controle em sua escala, os recursos da cobrança externa devem ser utilizados para promover a elaboração de estudos e projetos em escala de bacia hidrográfica, para posterior e provável busca por financiamentos. 
A cobrança pelo uso da água foi instituída para financiar os planos de bacia hidrográfica. Entretanto, sabe-se, conforme o estudo de Forgiarini et al. (2008), que a cobrança não é capaz de financiar completamente o plano da bacia do Rio Santa Maria, devido aos altos impactos econômicos proporcionados aos setores usuários, podendo inviabilizar suas atividades. Os autores demonstram que a capacidade de arrecadação da cobrança pelo uso da água no ambiente urbano da bacia do Rio Santa Maria teria a possibilidade de financiar apenas estudos e elaboração de projetos, como os planos diretores de Saneamento Ambiental, que incluem a drenagem urbana. Caberia a taxa de drenagem financiar ou dar uma contra-partida ao investimento estatal em obras de drenagem ou as ações estruturais propriamente ditas. Dessa forma, as ações estruturais e não estruturais em escala de bacia hidrográfica podem ser financiados parcialmente pela cobrança.

Contudo, existirá a possibilidade, via cobrança pelo uso da água, de obter uma economia de escala para a bacia. As ações em cada município poderiam ser estudas e/ ou implantadas pela Agência de Bacia (quando existir), por meio da cooperação intermunicipal, do compartilhamento de equipes técnicas, da troca de experiências e da capacitação. A agência de bacia pode ser um excelente instrumento de atualização tecnológica e de capacitação técnica em nível municipal, tendo por foco a redução de impactos de áreas urbanas na escala territorial da bacia hidrográfica.

\section{CONSIDERAÇÕES FINAIS}

A "taxa pela drenagem" possui, mais destacadamente, a relação entre a causa do impacto e custo da minimização do efeito, vinculando-se ao perímetro urbanizado do município. Já a "cobrança pelo uso da água" tem a visão mais solidária vinculada à abrangência territorial da bacia hidrográfica e de todo os seus intervenientes. Os recursos arrecadados pela "cobrança" não necessariamente serão aplicados onde é causado o impacto, caracterizando uma visão mais condominial do processo.

Naturalmente as duas cobranças (Taxa de Drenagem e Cobrança pelo uso da água) serão repassadas aos usuários urbanos, na forma de aumento das contas de água e esgoto ou, conforme sugerem Nascimento et al. (2006), incluída no Imposto Predial e Territorial Urbano (IPTU), podendo representar acréscimos ou decréscimos de acordo com o controle do escoamento proporcionado pelo proprietário.

Ainda, se tratando de dois pagamentos, pode haver sinergia entre a taxa e a cobrança. Por exemplo, se a taxa pelo serviço de drenagem for baseada em um indicador de demanda pelo serviço ( por exemplo, a área impermeabilizada do lote conectada à rede) ela poderá desempenhar papel de incitação à redução da impermeabilização ou à adoção de medidas locais de redução de escoamentos (por exemplo, promover a infiltração e o armazenamento). Por outro lado, recursos obtidos pela cobrança de um preço público pela água podem ser investidos na promoção de medidas dessa natureza, nas áreas urbanas na bacia, a partir de uma decisão do Comitê de Bacia Hidrográfica (por exemplo, capacitação de técnicos e tomadores de decisão, monitoramento, dentre outros). Esta situação é benéfica, pois, em última análise, ambos os pagamentos buscam melhorar os aspectos quantitativos e qualitativos dos recursos hídricos no ambiente urbano e na bacia hidrográfica como um todo.

Os municípios ou as concessionárias prestadores do serviço de drenagem urbana devem assumir seus papéis na gestão dos recursos hídricos, se responsabilizando pelo atendimento às metas do enquadramento, solicitando a outorga para o uso da água e se inserindo no processo de cobrança pelo uso da água. A operacionalização dos instrumentos de gestão pode ser utilizada para minimizar os impactos decorrentes da urbanização por meio da indução de ações estruturais e não estruturais para a drenagem urbana, bem como, em determinados casos, proporcionar um ganho de escala no serviço ao se adotar a bacia hidrográfica como unidade de gestão.

Estas ações vão ao encontro das recomendações do trabalho GEO Brasil (2007), que procurou apontar recomendações e propostas para novos avanços da gestão integrada dos recursos hídricos no Brasil. 0 documento aponta que se deve buscar a integração dos planos e programas desenvolvidos pelos setores usuários das águas, sob a perspectiva pragmática de inserir o tema dos recursos hídricos, de modo transversal e permanente, nos investimentos empreendidos por tais setores (saneamento, geração de energia, irrigação e outros). U ma forma de se buscar isto é a aplicação dos instrumentos de gestão à todos os segmentos de usuários de água em uma bacia hidrográfica, para que o gerenciamento interno (municípios) atenda aos condicionantes externos ( bacia). 


\section{AGRADECIMENTOS}

Os autores agradecem ao $\mathrm{CNPq}$ pelas bolsas concedidas de estímulo a pesquisa, em nível de pós doutorado, doutorado e produtividade em pesquisa.

\section{REFERÊNCIAS}

BALARINE, O. F. (Org.). (2000). Projeto rio Santa Maria: a cobrança como instrumento de gestão das águas. Porto Alegre/RS: Edipucrs. $140 \mathrm{p}$.

BAPTISTA M. B.; NASCIMENTO, N. O. (2002). Aspectos institucionais e de financiamento dos Sistemas de Drenagem Urbana. RBRH: Revista Brasileira de Recursos Hídricos, Porto Alegre, v.7, n.1, p.29-49.

BAPTISTA, M., NASCIMENTO N., BARRAUD, S. (2005). Técnicas compensatórias em Drenagem Urbana. Porto Alegre: ABRH, $266 \mathrm{p}$.

CANÇADO, V., NASCIMENTO, N. de O., CABRAL, J. R. (2006). Cobrança pela Drenagem Urbana de águas pluviais: bases conceituais e princípios microeconômicos. RBRH: Revista Brasileira de Recursos Hídricos, Porto Alegre, v.11, n.2, p.15-25.

CÁNEPA, E. M., PEREIRA, J. S., LANNA, A. E. (1999). A Política de Recursos Hídricos e o Princípio UsuárioPagador. Revista Brasileira de Recursos Hídricos, v. 4 no. 1 (jan/Mar), p. 103-117.

CRUZ, M. A. S. (2004). Otimização do Controle da Drenagem em Macro-bacias Urbanas. Tese de Doutorado. Universidade Federal do Rio Grande do Sul. Instituto de Pesquisas Hidráulicas. Programa de PósGraduação em Recursos Hídricos e Saneamento Ambiental. Porto Alegre. BR-RS, $217 \mathrm{p}$.

CRUZ, M.A.S.; SOUZA, C.F. \& TUCCI, C.E.M (2007). Controle da drenagem urbana no Brasil: avanços e mecanismos para sua sustentabilidade. In: Anais XVII Simpósio Brasileiro de Recursos Hídricos. São PauIO/SP. CD-ROM.

DOLL, A., LINDSEY, G. (1999). Credits as economic incentives for on-site stormwater management: issues and examples. In: Proceedings of the U.S. Environmental Protection Agency National Conference on Retrofit Opportunities for Water Resource Protection in Urban Environments, Chicago, IL, February 9-12, 1998, EPA/625/R-99/002, July 1999, pp. 113-117.

EUROESTUDIOS; NOVOTECNI (2003). Estudos de Viabilidade do Programa de Recuperação e Desenvolvimento da bacia Hidrográfica do rio Santa Maria, no Estado do Rio Grande do Sul: Relatório Final. Porto Alegre: Governo da Espanha, Governo do Estado do Rio Grande do Sul, RS e Secretaria de Obras Públicas e Saneamento, RS.
FEPAM (2001). Enquadramento dos recursos hídricos superficiais da Bacia Hidrográfica do rio Santa Maria. Relatório. $20 \mathrm{p}$.

FORGIARINI, F. R., SOUZA, C. F., SILVEIRA, A. L. L., SILVEIRA, G. L., TUCCI, C. E. M. (2007). Avaliação de Cenários de Cobrança pela Drenagem Urbana de Águas Pluviais. In: XVII Simpósio Brasileiro de Recursos Hídricos, 2007, São Paulo.

FORGIARINI, F. R., SILVEIRA, G. L., CRUZ, J. C. (2008) Modelagem da Cobrança pelo uso da Água Bruta na Bacia do Rio Santa Maria/RS: II - Aplicação em Escala Real e Validação. RBRH: Revista Brasileira de Recursos Hídricos, Porto Alegre, v.13, n.2, p.15-23.

GEO Brasil (2007). GEO Brasil: recursos hídricos: componente da série de relatórios sobre o estado e perspectivas do meio ambiente no Brasil. Ministério do Meio Ambiente; Agência Nacional de Águas; Programa das Nações Unidas para o Meio Ambiente. Brasília: MMA; ANA, 264 p.

GOLDENFUM, J. A., TASSI, R., MELLER, A., ALLASIA, D., SILVEIRA, A. L. L. (2007) Challenges for the sustainable urban stornwater management in developing countries: from basic education to technical and Institutional Issues. NOVATECH, 2007, Lyon, França, anais $\mathrm{p}$ 357-364.

GOMES, C. A. B. (2005). Drenagem Urbana: análise e proposição de modelos de gestão e forma de financiamento. Tese de Doutorado, Universidade Federal de Minas Gerais.

IBGE (2000). Censo 2000. Disponível no site do Instituto Brasileiro de Geografia e Estatística http://www.ibge.gov.br. Acesso: 29/10/2005.

KATHURIA, V. (2006). Controlling water pollution in developing and transition countries-lessons from three successful cases. Journal of Environmental Management 78 (2006) 405-426.

NASCIMENTO, N. de O., CANÇADO, V., CABRAL, J. R. (2006). Estudo da cobrança pela Drenagem Urbana por meio de uma taxa de drenagem. RBRH: Revista Brasileira de Recursos Hídricos, Porto Alegre, v.11, n.2, p.135-147.

PEREIRA, J. S. (2002). A Cobrança pelo Uso da Água como Instrumento de Gestão dos Recursos Hidricos: da Experiência Francesa à Prática Brasileira. Tese de Doutorado, IPH/UFRGS, Porto Alegre/RS.

POMPÊO, C.A. (2000). Drenagem Urbana Sustentável. RB$\mathrm{RH}$ : Revista Brasileira de Recursos Hídricos, Porto Alegre, v.5, n.1, p.15-23.

POMPEU, C. T. (1997). Fundamentos jurídicos do anteprojeto de cobrança pela utilização das águas do domínio do Estado de São Paulo. In: Audiência pública sobre o anteprojeto de lei de cobrança pelo uso da água. São Paulo, agosto. 
Taxa Não é Cobrança: Uma Proposta para a Efetiva Aplicação do Instrumento de

Gestão dos Recursos Hídricos para a Drenagem Urbana

PUGET SOUND ACTION TEAM \& WASHINGTON STATE UNIVERSITY [PSAT \& WSU] (2005). Low Impact Development: Technical Guidance Manual for Puget Sound. Disponivel em:

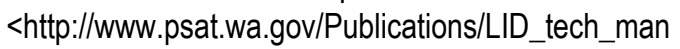
ual05/lid_index.htm>. Acesso em: 09/02/2007.

SEMASA (2007). Taxa de manutenção do sistema de drenagem - Semasa/Santo André. Disponível em: $<$ http://www.semasa.sp.gov.br/scripts/display.asp?id not $=197>$. Acesso em 05/06/2007.

SILVEIRA, A. L. L. GOLDENFUM, J. A. (2004). Sustainable approach applied for the development of urban drainage manuals in Brasil. NOVATECH, 2004, Lyon, França, anais $p$ 1325-1332.

SNSA (2005). Gestão do território e manejo integrado das águas urbanas: Cooperação Brasil-Itália em Saneamento Ambiental. Programa de Modernização do Setor de Saneamento - Secretaria Nacional de Saneamento Ambiental - Brasília: Ministério das Cidades, $270 \mathrm{p}$.

SOUZA, C. F. (2005). Mecanismos técnico-institucionais para a sustentabilidade da Drenagem Urbana. Dissertação de Mestrado. Universidade Federal do Rio Grande do Sul. Instituto de Pesquisas Hidráulicas. Programa de Pós-Graduação em Recursos Hídricos e Saneamento Ambiental. Porto Alegre. BR-RS, $193 \mathrm{p}$.

TUCCI C. E. M. (2002). Gerenciamento da Drenagem Urbana. RBRH: Revista Brasileira de Recursos Hídricos, Porto Alegre, v.7, n.1, p.5-27.

TUCCI, C. E. M. e MELLER, A. (2007). Regulação das águas pluviais urbanas. Disponivel em http://www.capnetbra-

sil.org/arquivos/Regulacao\%20das\%20aguas\%20plu viais\%20urbanas_TUCCI\&MELLER.pdf em 13/02/2007.

TUCCI, C.E.M. (2007). Inundações Urbanas. Porto Alegre: ABRH/RHAMA, 2007. 393p

UFSM/SEMA (2004a). Desenvolvimento de ações para a implantação da outorga na Bacia do rio Santa Maria: Relatório Final. Porto Alegre: Universidade Federal de Santa Maria, Governo do Estado do Rio Grande do Sul, RS e Secretaria de Obras Públicas e Saneamento, RS.

UFSM/SEMA (2004b). Simulação da cobrança pelo uso da água para a irrigação na Bacia do rio Santa Maria: Relatório Final. Porto Alegre: Universidade Federal de Santa Maria, Governo do Estado do Rio Grande do Sul, RS e Secretaria de Obras Públicas e Saneamento, RS.
Public Services Rates v. Water U se Charges: A Proposal for Effective Application of Water Resources $M$ anagement Instruments for U rban Drainage

\section{ABST RACT}

Currently, in academic studies and in some Brazilian cities (eg, Porto Alegre/RS), the creation of new urban drainage rates, similar to those Santo André/ SP is being discussed. Besides this fee, water use charges, a water resou rces management instrument, are also to be used. In the work developed in this field a conflict is noted regarding the concept and application of these charges. This paper aims to distinguish between the two payments and propose a strategy to apply them in a coordinated and effective way, seeking to minimize the impacts of urbanization on the hydrological cycle. In order to do so, the intention is to answer the following questions: "What are the goals of payments? Who should pay? Who manages the funds generated? Where should those resou rces be applied?" A critical analysis of the work found that: the urban drainage rates are a recovery rate and the water use charge is a public price. Therefore, payments are distinct, with distinct goals. The payment of the rate aims to promote the functioning of the urban drainage and the public price is related to the conservation of the river basin as a whole, in a condominial vision, and the funds generated can be applied in different actions. In this context, the following is defined: the rates are internal to the city, to be paid by building owners, and charges are outside the city, regarding impacts occurring in the river basin. Based on simulations performed for the Santa M aria River Basin (RS), the present study indicates a $1 / 20$ ratio to compare charges/tax revenues. The payments create funds that will be transferred to the city and the river basin committee, respectively, making investments in structural actions and, mainly, non-structural actions for urban drainage.

K eywords: water use charges, service rates, urban drainage. 